\title{
Lipopolysaccharide derived from the digestive tract triggers an inflammatory response in the uterus of mid-lactating dairy cows during SARA
}

Muhammad Shahid Bilal ${ }^{\dagger}$, Juma Ahamed Abaker ${ }^{\dagger}$, Zain ul Aabdin, Tianle Xu, Hongyu Dai, Kai Zhang, Xinxin Liu and Xiangzhen Shen ${ }^{*}$

\begin{abstract}
Background: The aims of the current study were to evaluate the inflammatory response in cow uterus and to explore the molecular mechanism triggered by high concentrate-induced subacute ruminal acidosis (SARA) in mid-lactating dairy cows. Twelve mid-lactating Holstein cows with an average weight of $455 \mathrm{~kg}$ were allocated into two groups subjected to two diets for 18-weeks either a low-concentrate (LC) group containing 4:6 (NDF: NFC) and a high-concentrate (HC) group containing 6:4 (non-forage carbohydrates, NFC): (neutral detergent fiber, NDF) ratio based on dry matter.

Results: The HC group showed lower ruminal pH and higher lipopolysaccharide (LPS) concentrations in both the rumen and peripheral plasma compared to the LC group. The LPS concentrations in the rumen fluid and the peripheral plasma were found significantly increased in the HC group compared to the LC group. The concentrations of IL-1 $\beta$, TNF- $a$ and IL- 6 were significantly higher in the HC group compared to the LC group. The uterus of SARA cows revealed elevated mRNA concentrations of nuclear transcription factors and pro-inflammatory cytokines, which confirmed the presence of inflammation. The occurrence of uterine inflammation was further validated by the increased protein expression of NF-KB-p65 and its active phosphorylated variant in the uterus of SARA cows. Similarly, the inflammatory genes TLR4, LBP, MyD88, TRAF-6, NF-KB, IL-6, IL-8, TNF- $a$ and IL-1 $\beta$ were significantly upregulated in the uterus of the HC versus the LC group.
\end{abstract}

Conclusion: Therefore, the results indicated that LPS derived from the rumen triggered the genes associated with inflammation in the uterus of mid-lactating dairy cows fed a high-concentrate diet, causing endometritis.

Keywords: Lipopolysaccharide, Sub-acute ruminal acidosis, Cow, LBP, Immune gene expression

\section{Background}

Feeding a high-concentrate diet for a longer period of time can cause subacute ruminal acidosis (SARA). It is a digestive disorder with a $\mathrm{pH}$ less than 5.6 lasted for more than $3 \mathrm{~h}$ per day $[1,2]$. General clinical signs of SARA comprise of reduced dry matter intake (DMI), decreased ruminal $\mathrm{pH}$ and diarrhea $[3,4]$. Another crucial outcome of SARA is the decline of milk quantity and quality $[2,3]$, and earlier studies also revealed that

\footnotetext{
* Correspondence: xzshen@njau.edu.cn

${ }^{\dagger}$ Equal contributors

College of Veterinary Medicine, Nanjing Agricultural University, Nanjing 210095, People's Republic of China
}

SARA decreased milk protein yield $[4,5]$. The persistent consumption of a $\mathrm{HC}$ diet by dairy animals enhances the production of organic acids and significantly results in a decline in $\mathrm{pH}$ values of the rumen and intestine [5-7]. This decrease in $\mathrm{pH}$ due to excessive high concentrate diet [8] may affect the alterations of the type of fermentation [9] and the structure of the microbes in the rumen $[10,11]$. Moreover, the decline in $\mathrm{pH}$ also perturbs the balance of microbial population in the rumen causing substantial release of free endotoxin (lipopolysaccharide, LPS) from gram-negative bacteria [12]. Due to possible alterations in permeability and disruption of the gastrointestinal barrier, LPS can be translocated into 
the blood stream $[2,13,14]$. There are also other reports revealed that elevated circulating LPS cause a systemic inflammatory response $[15,16]$. Possibly, being an element of an immune response to LPS, SARA has been reported to increase the concentration of acute phase proteins in the peripheral blood, such as serum amyloid A (SAA) and haptogloblin (Hp) $[2,12,14,17]$. The SAA has many functions but mainly alters innate immune responses, particularly in the migration of neutrophils and monocytes, while $\mathrm{Hp}$ has anti-inflammatory effects; LPS-binding protein (LBP) is activated by microbial infections and facilitates in the neutralization of LPS and in the triggering the release of pro-inflammatory cytokines, Such as TNF- $\alpha$, IL- 6 and IL-1 $\beta[6,18-20]$. The innate immune system is the first line of defence against invading pathogens; it involves various types of transmembrane and secreted molecules, recognized as pattern recognition receptors (PRR). Toll like receptors, such as TLR4, that join the LPS-LBP complex, are located on the outer surfaces of a variety of cells and contribute to the sensing of microbial pathogens in the intracellular endosomes and lysosomes [21, 22]. TLR4 recognizes LPS with the help of the LBP and cluster of differentiation antigen14 (CD14) [23, 24]. LPS activates myeloid differentiating factor 88 (MyD88) after joining with TLR4 on the host cell surface [25]. MyD88 activates TNF receptor-associated factor 6 (TRAF6), which stimulates the IкB kinase (IкK) complex, and phosphorylated $\mathrm{NF}-\mathrm{kB}$ is consequently translocated from the cytoplasm to the nucleus $[26,27]$. The NF- $\mathrm{KB}$-dependent cascade pathway regulates the production of pro-inflammatory cytokines, including interleukin (IL)-1 $\beta$, TNF- $\alpha$, IL- 6 , chemokines (IL-8) and other inflammatory mediators [28]. The principal objectives of this study were to evaluate the inflammatory response in cow uterus and to explore the molecular mechanism triggered by high concentrateinduced SARA in mid-lactating dairy cows.

\section{Methods}

\section{Animals, diets and experimental design}

Twelve healthy multiparous Holstein cows, which were purchased from the Experimental Farm of Nanjing Agricultural University, with an average body weight of $455 \mathrm{~kg}$ were selected for the current study. The experimental cows were randomly divided into two groups, each group containing six cows: the high-concentrate (HC) group and the low-concentrate (LC) group. The $\mathrm{HC}$ group was provided a high-concentrate diet containing 6:4 (non-forage carbohydrates, NFC): (neutral detergent fiber, NDF) ratio, while LC group was fed low concentrate diet containing 4:6 (NDF: NFC) for the 18week experimental period. The details of the nutritional ingredients and their compositions are shown in Table 1. The cows were surgically fixed with a ruminal fistula
Table 1 Ingredient and nutrient composition of diets

\begin{tabular}{lll}
\hline Ingredients, \% of DM & $\mathrm{LC}^{\mathrm{a}}$ & $\mathrm{HC}^{\mathrm{a}}$ \\
\hline Corn silage & 30.0 & 20.0 \\
Alfalfa & 30.0 & 20.0 \\
Maize & 22.7 & 33.6 \\
Wheat bran & 5.1 & 15.0 \\
Soybean meal & 9.8 & 9.0 \\
Calcium phosphate dibasic & 0.9 & 0.5 \\
Limestone & 0.0 & 0.5 \\
Salt & 0.3 & 0.3 \\
Premix & 1.0 & 1.0 \\
Total & 100.0 & 100.0 \\
Nutritional Composition & \\
NE MJ/kg & & \\
CP \% & 6.3 & 6.7 \\
EE \% & 16.0 & 16.2 \\
NDF \% & 3.9 & 4.1 \\
ADF \% & 37.7 & 31.9 \\
NFC \% & 22.7 & 17.5 \\
Starch, \% & 33.4 & 40.3 \\
Ca \% & 25.3 & 32.2 \\
P \% & 0.9 & 0.8 \\
\hline
\end{tabular}

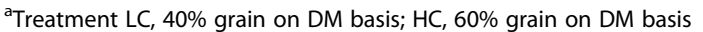
$N E$ Net energy mega joules, $C P$ crude protein, $E E$ ether extract, NDF neutral Detergent fiber, NFC non-forage carbohydrates, ADF Acid detergent fiber ${ }^{\mathrm{b}}$ The premix contained VA, 1.900,000 IU/kg; VD, 250,000 IU/kg; VE, $3484.32 \mathrm{IU} / \mathrm{Kg}$; Niacin, 4,000 mg/Kg; Cu, 1,200 mg/Kg; Fe, 525 mg/Kg; Zn, 13,000 mg/Kg; Mn, $5,500 \mathrm{mg} / \mathrm{kg} ; \mathrm{l}, 170 \mathrm{mg} / \mathrm{Kg} ; \mathrm{Co}, 50 \mathrm{mg} / \mathrm{Kg} ; \mathrm{Se}, 27 \mathrm{mg} / \mathrm{Mg}$

'The calculated nutritional composition values

two weeks prior to the experiment. The cows were kept in individual tie stalls and feed was offered three times per day at 0400, 1200 and $2000 \mathrm{~h}$. DMI was $\sim 21.7 \mathrm{~kg} / \mathrm{d} /$ head, and fresh drinking water was available to them during the entire experimental period. The experiment was started after the animals made a full recovery from the ruminal fistula fixation, and no cows showed any clinical signs of infection during the experiment.

\section{Collection of samples and analysis}

The rumen fluid was collected at one-hour intervals for $12 \mathrm{~h}$ daily for 3 continuous days during the $18^{\text {th }}$ week. Blood samples were collected $4 \mathrm{~h}$ after feeding on the sampling days $\left(5,6\right.$ and 7) of the $18^{\text {th }}$ week. $10 \mathrm{~mL}$ of rumen fluid was immediately centrifuged at $10,000 \times \mathrm{g}$ for $45 \mathrm{~min}$, filtered through a disposable $0.22-\mu \mathrm{m}$ filter and stored in Pyrogen free glass at $-20{ }^{\circ} \mathrm{C}$ for LPS analysis. The blood samples were collected from the jugular vein into 5 - $\mathrm{mL}$ vacuum tubes containing sodium heparin as an anticoagulant. The plasma was separated from the blood samples through centrifugation at $3000 \times$ g at $4{ }^{\circ} \mathrm{C}$ 
for $15 \mathrm{~min}$ and stored at $-20{ }^{\circ} \mathrm{C}$ to determine the concentrations of the pro-inflammatory cytokines IL-1 $\beta$, IL6 , and TNF $\alpha$ in the peripheral blood. At the end of the experiment, the cows were slaughtered after overnight fasting. The slaughtering was performed according to the law of Jiangsu Provincial People's Government, China and the study was approved by the Animal Ethics Committee (AEC) of Nanjing Agricultural University, China as described in the end of the manuscript. After slaughtering, the uterine tissues were removed from all the cows aseptically, as close to the cervix as possible for the analysis. All collected tissues were immediately frozen in liquid nitrogen and stored at $-70{ }^{\circ} \mathrm{C}$ within 30 min of slaughtering [29].

\section{Determination of ruminal $\mathrm{pH}$}

Rumen fluids were taken through a rumen fistula at one-hour intervals up to $12 \mathrm{~h}$ on days 5,6 and 7 of the $18^{\text {th }}$ week of the trial. The $\mathrm{pH}$ of rumen was measured each hour immediately following the sample collection by $\mathrm{pH}$-meter (Sartorius, Basic pH Meter PB-10, PB-21, Goettingen, Germany).

\section{Determination of LPS}

The concentration of LPS in the rumen fluid and plasma of the jugular vein was determined by Chromogenic Endpoint Limulus Amebocyte Lysate Assay Kits, CE64406 and CE80545 (Chinese Horseshoe Crab Reagent Manufactory Co., Ltd., Xiamen, China). Briefly, the pre-treated rumen fluid and plasma samples were diluted until their LPS concentrations were in the range of 0.1 to 1 endotoxin units $(\mathrm{EU}) / \mathrm{mL}$ relative to the reference endotoxin and assayed as described by Gozho et al. [2, 6].

\section{Radioimmunoassay}

Radioimmunoassay was used to calculate the concentrations of IL-6, IL-1 $\beta$, and TNF- $\alpha$ in peripheral blood using radioimmunoassay (RIA) kits (IL-1 $\beta$, C09DJB; IL-6, C12DJB; TNF- $\alpha$, C06PJB; Beijing North Institute of Biological Technology, Beijing, China).

\section{RNA extraction and real time PCR (RT-q PCR)}

Total RNA was prepared from $100 \mathrm{mg}$ uterus tissue using TRIzol (Takara Co., Otsu, Japan) via homogenization on ice as described by the manufacturer's instructions. The quality of mRNA was assessed by both agarose gel (1\%) electrophoresis and spectrometry (A260/A280) using the Eppendorf Bio photometer Plus (Eppendorf AG, Hamburg, Germany). Only samples with a ratio between 1.8 and 2.1 were used in subsequent experiments. The firststrand cDNA was synthesized using $250 \mathrm{ng} / \mu \mathrm{l}$ of the total RNA template using Prime Script RT Master Mix Perfect Real Time (Takara Co., Otsu, Japan) according to the manufacturer's instructions.
Quantitative real-time PCR (qRT-PCR) amplification was performed to evaluate the expression of the selected genes. The primers for genes IL-1 $\beta$, TLR4, IL-6, IL-8 [30], and LBP [31] were used according to previously published work, while MyD88, TNF- $\alpha$, TRAF6, and NF$\kappa B$ were designed using the Premier primer 5.0 software. The primers were assessed for their amplification efficiencies. The reaction conditions included $2 \mu \mathrm{l}$ of cDNA and $0.4 \mu \mathrm{M}$ primers in a total volume of $20 \mu \mathrm{l}$ of super mix. Thermal cycling parameters consisted of initial denaturation at $95{ }^{\circ} \mathrm{C}$ for $15 \mathrm{~s}$, followed by 40 cycles of annealing at $95{ }^{\circ} \mathrm{C}$ for $5 \mathrm{~s}$ and primer extension at $60{ }^{\circ} \mathrm{C}$ for $31 \mathrm{~s}$. All the reactions were run in triplicate. Each cDNA sample was amplified using SYBR Green (Takara Co., Otsu, Japan) in the ABI 7300 Fast Real-Time PCR System (Applied Bio systems, USA).

The data were normalized to the mean of housekeeping gene $\beta$-actin to control the unpredictability in expression levels and were analysed using $R=2^{-\Delta \Delta \mathrm{Ct}}$ method ( $\mathrm{Ct}_{\text {target }}$ gene $-\mathrm{Ct}_{\beta}$-actin $)$ treatment - $\left(\mathrm{Ct}_{\text {target gene }}-\mathrm{Ct}_{\beta}\right.$-actin $)$ control), as previously depicted [32]. The primer sequences used in this study are presented in Table 2 .

\section{Western blotting analysis}

The protein was extracted from $100 \mathrm{mg}$ uterus tissue with radio immunoprecipitation assay (RIPA) buffer using a Dounce Homogenizer (Polytron PT 1200 E, Switzerland). After $30 \mathrm{~min}$ of incubation on ice, cell extracts were subjected to centrifugation $(12,000 \times \mathrm{g})$ at $4{ }^{\circ} \mathrm{C}$ for $15 \mathrm{~min}$ to obtain cell protein. The supernatant was assayed for protein concentration using the bicinchoninic acid (BCA) protein assay kit (Pierce, Rockford, IL, USA) and was adjusted to $4 \mu \mathrm{g} / \mu \mathrm{l}$. Equal amounts of proteins were isolated using 10\% SDS-polyacrylamide gel electrophoresis (PAGE) and shifted to nitrocellulose membrane (NC) (Bio sharp, China) at $4{ }^{\circ} \mathrm{C}$. Then, $10 \%$ non-fat dry milk was used to block the nitrocellulose membrane. The membrane was incubated at $4{ }^{\circ} \mathrm{C}$ overnight with monoclonal goat antibodies against NF- $\mathrm{kB}$ and GAPDH (Santa Cruz Biotechnology, Santa Cruz, CA, USA, diluted by 1:200), (Bio world, CA, USA, diluted by 1:10000), respectively. After incubation, the membrane was washed and incubated with horseradish peroxidaseconjugated goat anti-rabbit secondary antibodies. Immunoreactive proteins were detected by chemiluminescence using an ECL reagent (Super Signal West Pico Trial Kit, Pierce, USA) and subsequently autoradiographed. The results were quantified using Bio-Rad Gel Doc 2000 Systems (Bio-Rad, USA) and analysed with Bio-Rad TDS Quantity One software (Bio-Rad). The relative quantities of proteins were evaluated by a densitometer and expressed as absorbance units (AU). 
Table 2 The list of primer sequences used for amplification of qRT-PCR

\begin{tabular}{lllll}
\hline Gene & Forward primers & Reverse primers & Accession number & Product size (bp) \\
\hline TLR-4 & GGACCCTTGCGTACAGGTTG & GGAAGCTGGAGAAGTATGGC & NM_174198.6 & 244 \\
TRAF-6 & GCGGCCTTCAAGTTAGGAGA & TCATCAACTGCTCGTTCGGG & NM_001034661.2 & 141 \\
NF-kB & ACGATCGTCACCGGATTGAG & GGTGCTGAGAGATGGCGTAA & XM_005699996.1 & 194 \\
$\beta$-actin & CTCTTCCAGCCTTCCTTCCT & GGGCAGTGATCTCTTTCTGC & AY141970 & 178 \\
IL-6 & GGAGGAAAAGGACGGATGCT & GGTCAGTGTTTGTGGCTGGA & EU276071.1 & 226 \\
IL-8 & CCTCTTGTTCAATATGACTTCCA & GGCCCACTCTCAATAACTCTC & NM_173925.2 & 170 \\
TNF-a & GCTCTTACCGGAACACTTCG & GGACACCTTGACCTCCTGAA & NM_173966 & 238 \\
IL-1 $\beta$ & AACCGAGAAGTGGTGTTCTGC & TTGGGGTAGACTTTGGGTCT & NM_174093 & 167 \\
MyD88 & AAAGCCCGAGTGTTTGATG & TCACATTCCTTGCTTTGCAG & NM_001014382 & 234 \\
LBP & GCAAGATCACTGGATTCTTGGA & AAAACAGGAAGTCCTTGTGGATC & NM_001038674.2 & 228 \\
\hline
\end{tabular}

\section{Statistical analyses}

The mixed procedure of SAS was used to analyze $\mathrm{pH}$ with a repeated measures design performed with SAS software (SAS version 9.2, SAS Institute Inc.). The effects of cows were considered random and the effects of diet and time were considered as fixed factors. The time within treatments and cows were considered as repeated measurements and the residuals for each variable were used to assess the normality. The days were averaged within a cow before the analysis for all the data including the $\mathrm{pH}$, radioimmunoassay, ruminal LPS, plasma LPS and the gene expression data were assessed by independent $t$-test and expressed as mean \pm SEM. Differences were concluded to be significant at $p<0.05$.

\section{Results}

\section{Rumen pH and LPS content of rumen fluid and blood plasma}

The results of ruminal $\mathrm{pH}$ fed a high concentrate diet were published previously by $\mathrm{Xu}$ et al. [33] and he confirmed the presence of SARA by measuring the ruminal $\mathrm{pH}$ at different time intervals. In this study, consuming a high-concentrate diet (HC group) for 18 weeks resulted in a significant decline in ruminal $\mathrm{pH}(<5.6)$ than that in the LC group $(p<0.05)$ and lasted for more than three hours [2]. The effect of diet $\times$ hours on $\mathrm{pH}$ was significant (0.05); however no effect was observed on hours alone.

The LPS concentrations in the rumen fluid and the jugular vein plasma were significantly higher in the cows fed a high-concentrate diet compared to cows fed a lowconcentrate diet. The concentration of LPS in the rumen fluid of the $\mathrm{HC}$ group was $79040 \mathrm{EU} / \mathrm{mL}$, compared to $47170 \mathrm{EU} / \mathrm{mL}$ in the LC group $(p<0.01)$; similarly, in the peripheral plasma, the LPS level in the HC group was $860 \mathrm{EU} / \mathrm{mL}$, whereas it was $470 \mathrm{EU} / \mathrm{mL}$ in LC group $(p<0.001)$, which indicated that the LPS level was significantly increased in the $\mathrm{HC}$ group relative to the LC group (Table 3).

\section{Levels of pro-inflammatory cytokines in the peripheral blood}

The results of the measurement of pro-inflammatory cytokines, together with IL-1 $\beta$, IL- 6 and TNF- $\alpha$ are shown in Fig. 1. The concentration of IL-1 $\beta$ was significantly higher in the $\mathrm{HC}$ group compared to the LC group $(p<0.007)$ (Fig. 1a), the concentration of IL-6 was significantly increased in the HC group versus LC group $(p<0.004)$ (Fig. 1b) and the concentration of TNF- $\alpha$ was elevated in the HC group relative to the LC group $(p<0.002)$ (Fig. 1c). Generally, the concentration of pro-inflammatory cytokines in the peripheral blood was significantly higher in the $\mathrm{HC}$ group compared to the LC group.

\section{Expressions of genes involved in the inflammation of the uterus}

SARA significantly increased the expression level of several genes involved in the inflammation of the uterus as shown in Fig. 2. The gene expression of TLR4 $(p<0.006)$ and MyD88 $(p<0.01)$ in the HC group was significantly upregulated compared to the LC group. Similarly, TRAF-6 ( $p$ $<0.04)$ and NF- $\mathrm{BB}(p<0.005)$ were highly expressed in the $\mathrm{HC}$ group relative to the $\mathrm{LC}$ group. The gene expression of TNF- $\alpha(p<0.005)$ and IL-8 $(p<0.005)$ was significantly increased. The gene expression of IL-1 $\beta(p<0.01)$, IL- $6(p<$ $0.01)$ and LBP $(p<0.03)$ was also significantly higher in the $\mathrm{HC}$ group compared with the LC group.

Table 3 LPS concentration in rumen and plasma of dairy cows fed low concentrate (LC) and high concentrate (HC)

\begin{tabular}{lllll}
\hline LPS concentration (EU/mL) & Treatment $^{\text {a }}$ & & & \\
& LC & HC & SEM $^{b}$ & $p$-Value \\
\hline Rumen LPS & 47170 & 79040 & 7966.25 & $<0.01$ \\
Jugular vein Plasma LPS & 470 & 860 & 81.26 & $<0.001$ \\
\hline
\end{tabular}

${ }^{a} H C$ high concentrate diet, $L C$ low concentrate diet, $E U$ endotoxin unit ${ }^{b}$ SEM Standard error of the mean between the two groups

The LPS data were compared using Student's $t$-test between $\mathrm{HC}$ and LC groups

$P \leq 0.05$ was considered significant 


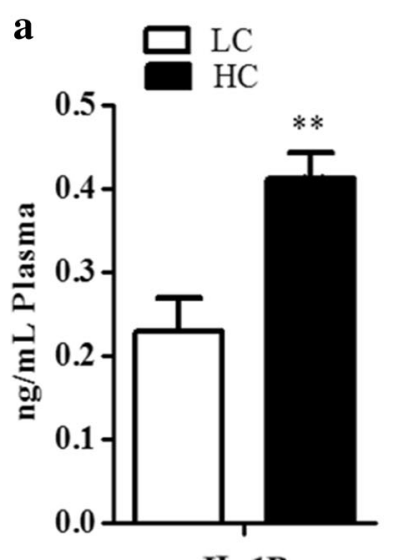

b

b

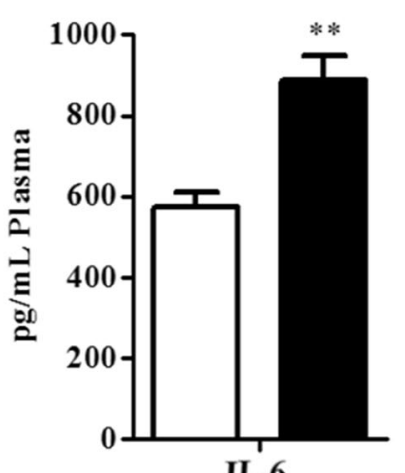

c $\square \mathrm{LC}$

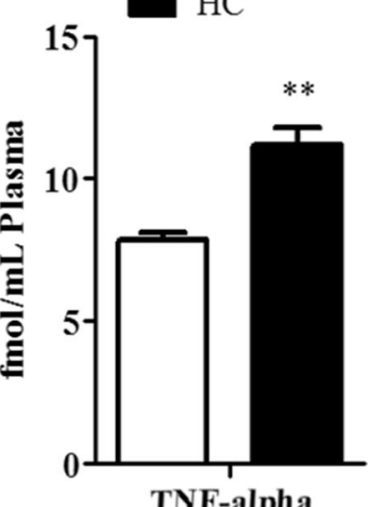

Fig. 1 a-c The concentration levels of TNF- $\alpha, I L-1 \beta$, and IL- 6 in the peripheral blood. The data were expressed as the mean $\pm S E M . ;$ asterisks indicate the differences between the low-concentrate (LC) group and high-concentrate (HC) group. ${ }^{*} p<0.05,{ }^{* *} p<0.01, n=12$ )

Expression of NF-kB protein in the cow uterus of the HC group and LC group

Western blot analysis demonstrated that high concentrate diet-induced inflammation through the increaseduterine concentrations of the NF- $\mathrm{kB}$ (p65) proteins in the HC group compared with the LC group $(p<0.03$; Fig. 3a). Importantly, the amount of phosphorylated NF$\kappa \mathrm{B}(\mathrm{p}-\mathrm{p} 65)$ was higher in the uterus of the $\mathrm{HC}$ group than in the LC group $(p<0.04$; Fig. 3b). Therefore, it was confirmed that NF- $\mathrm{kB}$ was activated in $\mathrm{HC}$ group in the TLR4 signalling pathway.

\section{Discussion}

The present study assessed the uterine inflammation at the molecular level in dairy cows. The inflammatory response in the uterus due to circulating LPS derived from

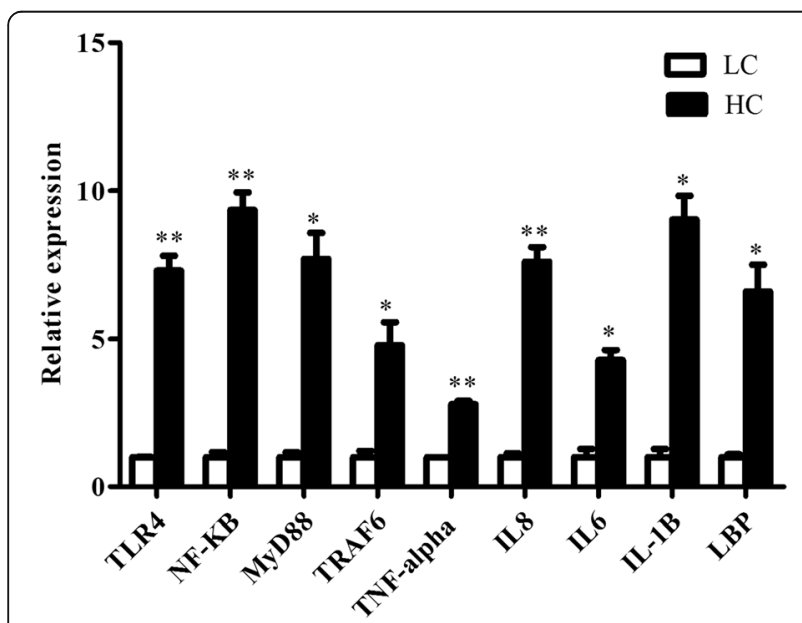

Fig. 2 The uterine gene expression profile analysed by qRT-PCR. The genes involved in transcriptional regulation were measured in the uterine tissues. The error bars indicate the standard error of the mean and ** indicates significance at $p<0.01$ rumen triggered the expression of pro-inflammatory cytokines through TLR4 signaling. To evaluate the inflammatory response in cow uterus and to explore the molecular mechanism triggered by high concentrate diet, SARA was confirmed by measuring the $\mathrm{pH}$ of the rumen. Xu et al. [33] also confirmed the presence of SARA by measuring the ruminal $\mathrm{pH}$ at different time intervals. In our study, the low rumen $\mathrm{pH}(>5.6)$ lasted for

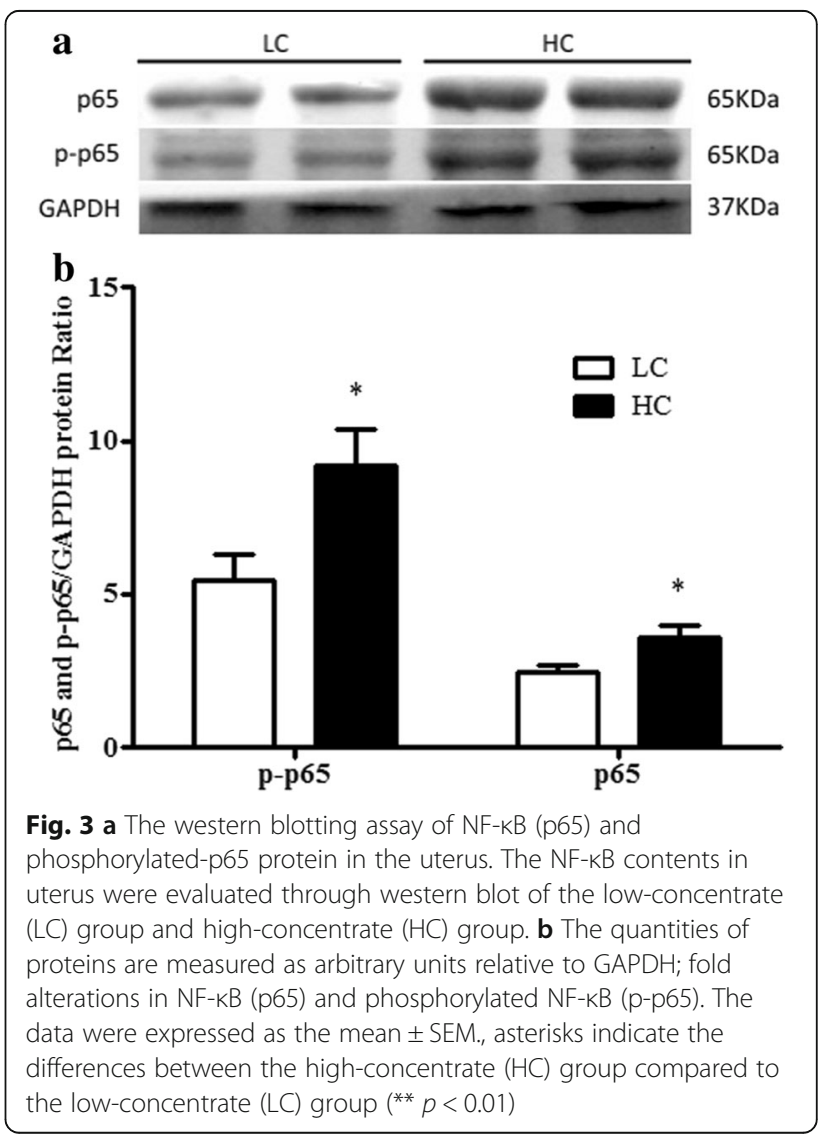


$223 \mathrm{~min}$ and high concentrations of LPS were observed in the rumen fluid and peripheral blood. The recent reports also indicated the successful induction of SARA, if theduration of low rumen $\mathrm{pH}$ was more than $180 \mathrm{~min} /$ day $[22,31]$. However, there is little literature revealing that SARA not only depends on $\mathrm{pH}$, but also on the alteration in the microbial population that develops secondarily to the feed type [34]. As a matter of fact, low ruminal $\mathrm{pH}$ values led to the lysis of gram-negative bacteria which released LPS into the blood circulation [31, 35]. Consistent with previous studies in dairy cows and feedlot, our results presented higher concentrations of LPS in the peripheral plasma (860 $\mathrm{EU} / \mathrm{mL})$ and ruminal fluid $(79040 \mathrm{EU} / \mathrm{mL})$ of cows fed a high concentrate die trelative to the peripheral plasma of the LC group [14, 36]. Moreover, we also found that high concentrate diet feeding increased the plasma concentrations of pro-inflammatory cytokines (IL-1 $\beta$, TNF- $\alpha$ and IL-6). Similar results have been reported by other researchers $[6,19,37]$. The increment in pro-inflammatory cytokines concentration in the plasma may provide confirmation for LPS translocation into the blood circulation and eliciting of inflammatory responses. This implies that inflammation in the $\mathrm{HC}$ group was due to the high level of LPS in the bloodstream, which in turn triggers the proinflammatory gene to cope with stress conditions [37].

The RT-qPCR-based findings revealed the presence of inflammation-associated markers in the uterus of SARA-induced cows and confirmed that the dairy cows suffered from uterine inflammation at the molecular level. According to our results, the increased expression of TLR4 indicated that TLR4 recognized the LPS and triggered the inflammatory pathway $[9,38]$. Identification of inflammatory-stimuli by the innate immune system is organized by PPR that identify external stimuli for example pathogen associated molecular patterns (PAMPs) [39]. Furthermore, our research demonstrated the increased expression of LBP, MyD88, and TRAF6 in the uterus; which provides more clues that the TLR4 signaling pathway was stimulated by LPS $[25,40]$. Previous studies demonstrated that as a main transcription factor, NF- $\mathrm{kB}$ may bind to the promoter regions of the many inflammatory genes to regulate their transcription activities [37, 41]. Similarly, in the current study, NF-кB expression was increased in the $\mathrm{HC}$ group, which also confirmed the activation of TLR4 signalling pathway. Our results of increased expression of pro-inflammatory cytokines (IL-1 $\beta$, TNF- $\alpha$ and IL-6) and chemokine (IL-8) in the HC group due to SARA-induced LPS were consistent with the previous studies [25, 42-46].

The western blot results further confirmed that the expression levels of NF- $\mathrm{KB}$ (p65) and phosphorylated p65 proteins were distinctly increased in the $\mathrm{HC}$ group compared to the LC group. Taken together, the results suggested that LPS triggered the activation of TLR4 signalling, which resulted in an inflammatory response in the uterus of cows suffering from SARA. Conclusively, LPS activates TLR4-NF-kB signalling. Together with the existing study and the previous reports [33, 37], the protein expressions of NF- $\mathrm{kB}$ (p65) and p-p65 were magnified in the $\mathrm{HC}$ group.

\section{Conclusions}

According to our results, long-term feeding of high concentrate diet causes uterine inflammation in mid-lactating dairy cows. The inflammatory response in the uterus induced by increased level of circulating LPS triggers the expression of pro-inflammatory cytokines in the uterus through the TLR4-NF- $\kappa B$ signalling pathway.

\section{Abbreviations \\ AMP: Antimicrobial peptides; APP: Acute phase proteins; CD14: Cluster of differentiation antigen14; EECs: Endometrial epithelial cells: \\ GIT: Gastrointestinal tract; HC: High concentrate; IL-1 a: $-1 \beta,-6$, Interleukin-1 a 1 1 , -6; IKK: IKB kinase; LBP: LPS-binding protein; LC: Low concentrate; LPS: Lipopolysaccharide; MyD88: Myeloid differentiating factor 88; NF- KB: Nuclear factor kappa-light-chain-enhancer of activated B cells; \\ PAGE: Polyacrylamide gel electrophoresis; PAMPs: pathogen-associated molecular patterns; PRR: Pattern recognition receptors; qRT-PCR: Quantitative real-time PCR; SARA: Subacute ruminal acidosis; TLRs: Toll-like receptors; TRAF6: TNF receptor-associated factor 6}

\section{Acknowledgements}

The authors are grateful to Dr. Usman Waheed (Department of Pathobiology, University of Veterinary and Animal Sciences, Sub-campus Jhang, Pakistan) for helping in the revision of the manuscript.

\section{Funding}

This study was supported by the National Natural Science Foundation of China (31172371) and the Priority Academic Programme Development of Jiangsu Higher Education Institutions (PAPD).

\section{Availability of data and materials}

All relevant data are within the paper. Original data is available upon request and readers should contact with the first author (drshahidbilal@yahoo.com) and corresponding author (xzshen@njau.edu.cn).

\section{Authors' contributions}

$\mathrm{XS}$ and MSB conceived the idea and proposed the experiment. MSB, JAA, $Z A, H D, K Z$ and $X L$ conducted the majority of measurements for the parameters in this work and drafted the manuscript. TX and HD contributed to the statistical analyses. All authors read and approved the final manuscript.

\section{Competing interests}

The authors declare that they have no competing interests that would have predisposed the content of the paper or intervened with their objective consideration of the manuscript.

\section{Consent to publish}

Not applicable.

\section{Ethics statement}

The experimental design and sampling procedures were approved by the Animal Ethics Committee (AEC) of Nanjing Agricultural University, China before the start of the current experiment. The experiment was conducted according to the "Guidelines on Ethical Treatment of Experimental Animals" (2006) No. 398 established by the Ministry of Science and Technology, China and "the Regulation regarding the Treatment and Management of Experimental Animals" (2008) No.45 fixed by the Jiangsu Provincial People's Government. 


\section{Received: 5 May 2016 Accepted: 1 December 2016}

Published online: 12 December 2016

\section{References}

1. Steele MA, Croom J, Kahler M, AIZahal O, Hook SE, Plaizier K, et al. Bovine rumen epithelium undergoes rapid structural adaptations during grain-induced subacute ruminal acidosis. Am J Physiol Regul Integ Comp Physiol. 2011;300(6):R1515-23.

2. Gozho G, Plaizier J, Krause D, Kennedy A, Wittenberg K. Subacute ruminal acidosis induces ruminal lipopolysaccharide endotoxin release and triggers an inflammatory response. J Dairy Sci. 2005;88(4):1399-403.

3. Kleen J, Hooijer G, Rehage J, Noordhuizen J. Subacute ruminal acidosis (SARA): a review. J Vet Med Ser A. 2003;50(8):406-14.

4. Colman E, Fokkink W, Craninx M, Newbold J, De Baets B, Fievez V. Effect of induction of subacute ruminal acidosis on milk fat profile and rumen parameters. J Dairy Sci. 2010:93(10):4759-73.

5. Li S, Khafipour E, Krause D, Kroeker A, Rodriguez-Lecompte J, Gozho G, et al. Effects of subacute ruminal acidosis challenges on fermentation and endotoxins in the rumen and hindgut of dairy cows. J Dairy Sci. 2012;95(1):294-303.

6. Dong H, Wang S, Jia Y, Ni Y, Zhang Y, Zhuang S, et al. Long-term effects of subacute ruminal acidosis (SARA) on milk quality and hepatic gene expression in lactating goats fed a high-concentrate diet. PLoS One. 2013;8(12), e82850.

7. Garrett E, Pereira M, Nordlund K, Armentano L, Goodger W, Oetzel G, et al Diagnostic methods for the detection of subacute ruminal acidosis in dairy cows. J Dairy Sci. 1999;82(6):1170-8.

8. De Nardi R, Marchesini G, Plaizier JC, Li S, Khafipour E, Ricci R, et al. Use of dicarboxylic acids and polyphenols to attenuate reticular $\mathrm{pH}$ drop and acute phase response in dairy heifers fed a high grain diet. BMC Vet Res. 2014;10(277):014-0277.

9. Chang G, Zhuang S, Seyfert HM, Zhang K, Xu T, Jin D, et al. Hepatic TLR4 signaling is activated by LPS from digestive tract during SARA, and epigenetic mechanisms contribute to enforced TLR4 expression. Oncotarget. 2015;6(36):38578-90.

10. Emmanuel D, Madsen K, Churchill T, Dunn S, Ametaj B. Acidosis and lipopolysaccharide from Escherichia coli B: 055 cause hyperpermeability of rumen and colon tissues. J Dairy Sci. 2007;90(12):5552-7.

11. Mao S, Zhang R, Wang D, Zhu W. The diversity of the fecal bacterial community and its relationship with the concentration of volatile fatty acids in the feces during subacute rumen acidosis in dairy cows. BMC Vet Res 2012;8(237):1746-6148

12. Emmanuel D, Dunn S, Ametaj B. Feeding high proportions of barley grain stimulates an inflammatory response in dairy cows. J Dairy Sci. 2008:91(2):606-14.

13. Jiang J, Bahrami S, Leichtfried G, Redl H, Ohlinger W, Schlag G, et al. Kinetics of endotoxin and tumor necrosis factor appearance in portal and systemic circulation after hemorrhagic shock in rats. Ann Surg. 1995:221(1):100-6.

14. Khafipour E, Krause D, Plaizier J. A grain-based subacute ruminal acidosis challenge causes translocation of lipopolysaccharide and triggers inflammation. J Dairy Sci. 2009;92(3):1060-70.

15. Gozho G, Krause D, Plaizier J. Ruminal lipopolysaccharide concentration and inflammatory response during grain-induced subacute ruminal acidosis in dairy cows. J Dairy Sci. 2007:90(2):856-66.

16. Plaizier J, Khafipour E, Li S, Gozho G, Krause D. Subacute ruminal acidosis (SARA), endotoxins and health consequences. Anim Feed Sci Technol. 2012;172(1):9-21.

17. Gozho GN, Krause DO, Plaizier JC. Rumen lipopolysaccharide and inflammation during grain adaptation and subacute ruminal acidosis in steers. J Dairy Sci. 2006:89(11):4404-13.

18. Jia Y, Wang S, Ni Y, Zhang Y, Zhuang S, Shen X, et al. High concentrateinduced subacute ruminal acidosis (SARA) increases plasma acute phase proteins (APPs) and cortisol in goats. Animal. 2014;8(09):1433-8.

19. Zhou J, Dong G, Ao C, Zhang S, Qiu M, Wang X, et al. Feeding a highconcentrate corn straw diet increased the release of endotoxin in the rumen and pro-inflammatory cytokines in the mammary gland of dairy cows. BMC Vet Res. 2014;10(1):172.

20. De Nardi R, Marchesini G, Plaizier JC, Li S, Khafipour E, Ricci R, et al. Use of dicarboxylic acids and polyphenols to attenuate reticular $\mathrm{pH}$ drop and acute phase response in dairy heifers fed a high grain diet. BMC Vet Res. 2014;10(1):1

21. Beutler B, Rietschel ET. Innate immune sensing and its roots: the story of endotoxin. Nat Rev Immunol. 2003;3(2):169-76

22. Li S, Yoon I, Scott M, Khafipour E, Plaizier J. Impact of Saccharomyces cerevisiae fermentation product and subacute ruminal acidosis on production, inflammation, and fermentation in the rumen and hindgut of dairy cows. Anim Feed Sci Technol. 2016;211:50-60.
23. Sohn MJ, Hur GM, Byun HS, Kim WG. Cyclo (dehydrohistidyl-I-tryptophyl) inhibits nitric oxide production by preventing the dimerization of inducible nitric oxide synthase. Biochem Pharmacol. 2008;75(4):923-30.

24. Bannerman DD, Paape M, Hare W, Hope JC. Characterization of the bovine innate immune response to intramammary infection with Klebsiella pneumoniae. J Dairy Sci. 2004:87(8):2420-32.

25. Ju J, Li L, Xie J, Wu Y, Wu X, Li W, et al. Toll-like receptor-4 pathway is required for the pathogenesis of human chronic endometritis. Exp Ther Med. 2014;8(6):1896-900.

26. Turner M, Healey G, Sheldon I. Immunity and inflammation in the uterus. Reprod Domest Anim. 2012;47(s4):402-9.

27. Cohen J. The immunopathogenesis of sepsis. Nature. 2002;420(6917):885-91.

28. Cronin JG, Turner ML, Goetze L, Bryant CE, Sheldon IM. Toll-like receptor 4 and MYD88-dependent signaling mechanisms of the innate immune system are essential for the response to lipopolysaccharide by epithelial and stromal cells of the bovine endometrium. Biol Reprod. 2012;86(2):51.

29. D'Agata M, Russo C, Preziuso G. Effect of Islamic ritual slaughter on beef quality. Ital J Anim Sci. 2009;8(2):489-91.

30. Chang G, Zhang K, Xu T, Jin D, Guo J, Zhuang S, et al. Epigenetic mechanisms contribute to the expression of immune related genes in the livers of dairy cows fed a high concentrate diet. PLoS One. 2015;10(4), e0123942.

31. Zhang K, Chang G, Xu T, Xu L, Guo J, Jin D, et al. Lipopolysaccharide derived from the digestive tract activates inflammatory gene expression and inhibits casein synthesis in the mammary glands of lactating dairy cows. Oncotarget. 2016;7(9):9652-65.

32. Livak KJ Schmittgen TD. Analysis of relative gene expression data using realtime quantitative pcr and the $2-\delta \delta \mathrm{ct}$ method. Methods. 2001;25(4):402-8

33. Xu T, Tao H, Chang G, Zhang K, Xu L, Shen X, et al. Lipopolysaccharide derived from the rumen down-regulates stearoyl-CoA desaturase 1 expression and alters fatty acid composition in the liver of dairy cows fed a high-concentrate diet. BMCVet Res. 2015;11(1):52.

34. Calsamiglia S, Blanch M, Ferret A, Moya D. Is subacute ruminal acidosis a pH related problem? Causes and tools for its control. Anim Feed Sci Technol. 2012;172(1):42-50

35. Gott P, Hogan JS, Weiss WP. Effects of various starch feeding regimens on responses of dairy cows to intramammary lipopolysaccharide infusion. J Dairy Sci. 2015:98(3):1786-96.

36. Dong G, Qiu M, Ao C, Zhou J, Wang X, Zhang Z, et al. Feeding a high-concentrate corn straw diet induced epigenetic alterations in the mammary tissue of dairy cows. PLoS One. 2014;9(9), e107659.

37. Chang G, Zhang K, Xu T, Jin D, Seyfert HM, Shen X, et al. Feeding a high-grain diet reduces the percentage of LPS clearance and enhances immune gene expression in goat liver. BMC Vet Res. 2015;11(67):015-0376.

38. Akira S, Uematsu S, Takeuchi O. Pathogen recognition and innate immunity. Cell. 2006;124(4):783-801.

39. Bieghs $V$, Trautwein $C$. The innate immune response during liver inflammation and metabolic disease. Trends Immunol. 2013;34(9):446-52.

40. Sheldon IM, Cronin J, Goetze L, Donofrio G, Schuberth HJ. Defining postpartum uterine disease and the mechanisms of infection and immunity in the female reproductive tract in cattle. Biol Reprod. 2009;81(6):1025-32.

41. Kawai T, Akira S. Signaling to NF-kB by Toll-like receptors. Trends Mol Med. 2007;13(11):460-9.

42. Fu Y, Liu B, Feng X, Liu Z, Liang D, Li F, et al. Lipopolysaccharide increases Toll-like receptor 4 and downstream Toll-like receptor signaling molecules expression in bovine endometrial epithelial cells. Vet Immunol Immunopathol. 2013;151(1):20-7

43. Wang G, Sun B, Gao Y, Meng QH, Jiang HC. The effect of emodin-assisted early enteral nutrition on severe acute pancreatitis and secondary hepatic injury. Mediat Inflamm. 2007:2007:29638.

44. Zhang Y, Guo F, Ni Y, Zhao R. LPS-induced inflammation in the chicken is associated with CCAAT/enhancer binding protein beta-mediated fat mass and obesity associated gene down-regulation in the liver but not hypothalamus. BMC Vet Res. 2013;9(257):1746-6148.

45. Krikun G, Trezza J, Shaw J, Rahman M, Guller S, Abrahams VM, et al. Lipopolysaccharide appears to activate human endometrial endothelial cells through TLR-4-dependent and TLR-4-independent mechanisms. Am J Reprod Immunol. 2012;68(3):233-7

46. Galvão K, Santos N, Galvão J, Gilbert R. Association between endometritis and endometrial cytokine expression in postpartum Holstein cows. Theriogenology. 2011;76(2):290-9. 